\title{
ANTECEDENTES DEL ABASTECIMIENTO DE MADERA EN LA RIBERA DEL JÚCAR
}

\author{
Teresa Izquierdo Aranda ${ }^{l}$ \\ Universidad Politécnica de Valencia
}

\section{RESUMEN}

El abastecimiento de madera fue un aspecto fundamental en el Reino de Valencia en los siglos medievales. La amplia planicie del litoral y la escasez de bosques cercanos llevaron por un lado a desarrollar estrategias para su aprovisionamiento y por otro a impulsar medidas para garantizarlo. En este sentido, el Júcar y su afluente el Cabriel jugaron un importantísimo papel en el tráfico de troncos procedentes de las sierras de Cuenca. Asimismo, los territorios circundantes se convirtieron en áreas primordiales dentro del proceso. En este artículo analizaremos las tácticas empleadas desde época almorávide y las circunstancias en que se desarrolló la conducción de troncos por el Júcar tras la conquista.

Palabras clave: madera; abastecimiento; navegación fluvial; Júcar; cinquanté.

\section{WOOD SUPPLY BACKGROUND ON THE BANKS OF JÚCAR}

\section{ABSTRACT}

Wood's supply was an essential aspect for the Kingdom of Valencia during the medieval centuries. The large plain around the coast and the forest shortage caused, firstly, the development of supplying strategies and, secondly, the creation of specifical orders in order to guarantee it. In that sense, Júcar and its tributary Cabriel played an important role in the trunks traffic coming from the mountains of Cuenca. Also, the surrounding countryside was primordial in the procedure. In this article we are going to analyse the methods in use in the Almoravid period and the circumstances of the trunks navigation on the river after the conquest.

Key words: wood; supply; river navigation; Júcar; cinquanté.

Fecha de recepción: 26 de noviembre de 2014. Fecha de aceptación: 25 de marzo de 2015.

${ }^{1}$ Teresa Izquierdo Aranda. Departamento de Comunicación Audiovisual, Documentación e Historia del Arte Camino de Vera, s/n. 46022, Valencia teresa.izquierdo@uv.es 


\section{CONDICIONES PARA EL ABASTECIMIENTO}

Bosques y arboledas fueron altamente valorados durante los siglos medievales, porque los beneficios que el hombre obtenía de ellos eran múltiples y esenciales para la vida cotidiana (GAY, 2001). Por ejemplo, de los árboles frutales como el castaño, el nogal o la encina se obtenían, castañas, nueces, bellotas; otras especies proporcionaban leña y carbón, imprescindibles para el hogar así como en ciertas actividades artesanales. También la construcción consumía una gran cantidad de madera de calidad, sin olvidar la empleada en la industria naval, que requería especies resistentes como el roble o el álamo (FLORIDO, 2004; IZQUIERDO, 2014). Precisamente por la circulación de maderos destinados a la construcción de edificios y embarcaciones, el territorio de la Ribera del Júcar jugó un importantísimo papel en el abastecimiento de madera del litoral, en áreas costeras densamente pobladas pero deficitarias en materia forestal.

El recurso al río Júcar como medio de transporte de troncos se remonta probablemente a época romana, cuando se intensificó el consumo de madera para la edificación y la confección de carros y aparejos. La conducción fluvial no era desconocida en Roma, así en sus Diez libros de arquitectura Vitrubio (23-27 a.C.) refiere el transporte de troncos hasta Ravena a través del Po. Igualmente, cita un tipo de madera que por su peso no se mantenía a flote, se hundía en el agua y sólo podía ser transportado con barcas o almadías de abeto. Esta observación indica que, efectivamente, el transporte se realizaba mediante flotación una vez lanzados al río.

Por lo que a la ribera del Júcar se refiere, esta práctica está documentada en época musulmana con el testimonio del geógrafo Mohamed-al-Idrisi, cuyas descripciones dejan claro que la conducción fluvial fue el medio de transporte preferente para abastecer la región. Tras la conquista, la pacificación de las fronteras con Aragón amplió las posibilidades de aprovisionamiento, al poner los montes ibéricos a disposición de los habitantes de Valencia y abrir la circulación desde Guadalaviar. De este modo, la navegación se convirtió en el reino de Valencia en la vía tradicional de aprovisionamiento, que Francesc Eiximenis (c.1340-1409) subrayaba en el Regiment de la cosa pública entre las riquezas del reino: "que aquí hay cuatro ríos navales [...] por los cuales desciende madera de Castilla, bella, en gran abundancia, y que riegan la plana copiosamente". Las afirmaciones del franciscano corroboran la importancia que adquirió el curso de los ríos en el abastecimiento de madera, al tratarse de una ciudad alejada de la franja boscosa del interior pero situada a la orilla del Turia, cercana a la desembocadura del Júcar, posición que la enlazaba con las sierras arbóreas de Cuenca, Teruel y Ademuz. Partiendo de esta ubicación inmejorable se desarrollaron históricamente las estrategias para abastecer de madera a la región. Por tanto, al examinar las especies empleadas cabe considerar las características geográficas de las áreas que atravesaban ambos ríos, así como sus condiciones hídricas y orográficas, porque jugaron un activo papel en la organización del comercio maderero.

El Júcar nace en el paraje conocido como Ojos de Valdeminguete en la vertiente sur del cerro de San Felipe en los Montes Universales, cerca del nacimiento de los ríos Cuervo, Tajo, Turia y Cabriel, con el que converge a la altura de Cofrentes. En su curso alto, recorre las sierras del norte de Cuenca, algunas con nombres tan significativos como Sierra de la Madera. En este tramo abundan las gargantas y los desfiladeros formados por la erosión de las rocas calizas. Es una zona discontinua y escalonada donde el río va formando amplias planicies arcillosas. Al llegar a la llanura manchega describe un ángulo de $90^{\circ}$ y se orienta hacia levante. Se abre entonces un recorrido de numerosos meandros encajados en una serie de muelas y altozanos elevados creados por los cortes profundos de las montañas que atraviesa hasta llegar a Cofrentes. (Cebrián, 2008) Tras superar este trecho y recibir las aguas del Cabriel, en su curso bajo recorre el macizo de Caroche desde el cual entra en el valle de Ayora hasta la Hoya de Buñol y la Vall dels Alcalans rodeando los saltos de Cofrentes, Cortes de Pallás y Mijares en la canal de Navarrés, para desembocar finalmente en Cullera después de un recorrido de 497,5 km. 


\section{AL-IDRISI, PRIMER TESTIMONIO DE LA NAVEGACIÓN FLUVIAL DE TRONCOS POR EL JÚCAR}

Las primeras referencias documentales sobre el abastecimiento de madera en la región se remontan a la segunda mitad del siglo XII. Gracias a las descripciones del geógrafo musulmán Mohamed-al-Idrisi (c.1100-1165) sobre la navegabilidad de los ríos valencianos, descubrimos la circulación de troncos a través del río Júcar desde Quelaza, “...este último lugar [Quelaza] está fortificado y construido al otro lado de las montañas, donde crecen innumerables pinos. Se cortan los árboles y se hacen descender por el agua hasta Denia y Valencia. En efecto, estas maderas van por el río de Quelaza [Cabriel] hasta Alcira y desde allí hasta el fuerte de Cullera, desde donde descienden al mar; en seguida se les embarca para Denia, donde son empleadas en la construcción de navíos o bien, si son gruesos, para Valencia, donde sirven para la edificación".

Circulaban fundamentalmente pináceas, que han constituido históricamente una de las familias más características del paisaje peninsular; se trata de árboles de gran rendimiento en carpintería, de textura variable según la especie, con una coloración oscilante entre rosácea y terrosa. Son árboles de crecimiento pausado que ofrecen una madera homogénea de una resistencia mecánica excelente. Vitrubio (23-27 a.C.) aconsejaba su uso en la construcción por su rigidez y su resistencia al ataque de xilófagos al ser especies de poros pequeños y cerrados. En la carpintería valenciana, se emplearon fundamentalmente el pino negral o Pinus nigra, el Pinus sylvestris o pino rojo y el pinaster o pino marítimo, especies abundantes en las muelas y sierras de Cuenca, Castellón y Teruel en el Sistema Ibérico, así como en las de Cazorla y Segura en el Sistema Bético (IZQUIERDO, 2011). Al-Idrisi describía en sólo un párrafo el descenso de los pinos desde los bosques de Quelaza, donde se talaban y descortezaban antes de arrojarse al río. Siguiendo el curso del Júcar, a través de Alcira llegaban a Cullera. Desde allí se transferían al puerto de Denia las vigas destinadas a la industria naval, el principal centro de construcción de embarcaciones en época almorávide. Por su parte, los troncos más gruesos se asignaban para los proyectos arquitectónicos de la capital del reino.

La información que proporciona es concisa pero basta para conocer la procedencia y la destinación de los maderos, aunque las indicaciones relativas a la localización de Quelaza resultan ambiguas. El lugar, hoy desaparecido, es descrito como una fortaleza erigida al este de Cuenca, más allá de las montañas en las que Al-Idrisi destacaba la abundancia de pinos y el desarrollo de un primer comercio maderero. El geógrafo islámico se limitaba a señalar un asentamiento fortificado situado a tres días de camino al este de Cuenca, otros tres de Alpuente y tres respecto a Albarracín. De hecho, diversos investigadores han discutido sobre el emplazamiento sin coincidir finalmente en sus conclusiones. Así, Saavedra (1881) lo localizaba a orillas del Cabriel en el término de Iniesta, en cambio Sanchis y Piqueras (2001) lo sitúan en la confluencia de los ríos Cabriel y Guadazaón, una opción plausible al tratarse de un área tradicional de aprovisionamiento de madera en Cuenca que limita con los bosques de Cañete, Boniches, Enguídanos, Pajarón o San Martín.

Más allá de las disquisiciones geográficas, del testimonio de Al-Idrisi interesa destacar que fue el primero en subrayar la escasez de materia prima en la franja del litoral levantino. Incidía así en que la necesidad obligó a recurrir al transporte fluvial como la vía más fácil y segura para el abastecimiento, aprovechando la flotabilidad de la madera para aligerar la navegación. Su relato hacía notar además dos aspectos importantes: por un lado, que las sierras de Cuenca eran las regiones primordiales de aprovisionamiento en época almorávide; por otro, insistía en la importancia del Júcar como vía principal de entrada, en conexión con su afluente el Cabriel, pese a que el Turia circundaba Valencia y proporcionaba un enlace directo con la capital. El silencio de Al-Idrisi sobre por qué no se recurrió al Turia invita a pensar que la conducción por este río, en principio más lógica y natural, simplemente no se realizaba. Los motivos que desaconsejarían esta vía podrían deberse a las tensiones políticas suscitadas por el avance cristiano en el norte peninsular. De hecho, Pedro II había incorporado en 1210 el Rincón de Ademuz a la Corona de Aragón con la toma de los castillos de Ademuz y Castelfabib, territorio 
que posteriormente su hijo Jaime I agregaría al patrimonio real dentro del ámbito geográfico del Reino de Valencia (BONNASSIE et al., 2001). Así pues, en el momento de su redacción el nacimiento del Turia se hallaba bajo dominio aragonés, circunstancia que impedía el acceso a las sierras septentrionales del Sistema Ibérico (ÁLVAREZ, 2003).

\section{EL ABASTECIMIENTO DE MADERA TRAS LA CONQUISTA CRISTIANA}

Si bien la conquista cristiana en 1238 no enmendó la escasez de madera, la pacificación de las fronteras con Aragón amplió las posibilidades de aprovisionamiento, al poner los montes ibéricos a disposición de los habitantes de Valencia y abrir la circulación fluvial desde Guadalaviar. Asimismo, la conducción de maderos fue considerada desde un principio una regalía, al incluirse en la prerrogativa por la que la monarquía se reservaba el dominio directo sobre las aguas. Este privilegio comprendía la navegación de cualquier tipo de embarcación o producto que transitara por ellas, como las cabañas y barcas de maderos y todas las infraestructuras que cruzaran, como puentes, norias o molinos. Gracias a la mayor estabilidad de las instituciones municipales y del sistema señorial, la monarquía cedería progresivamente los derechos de monopolio para garantizar el cuidado de las instalaciones viarias, sobre todo en relación a los puentes (ARCINIEGA, 2011). No obstante, el control de los ríos por los que descendía la madera se mantuvo implacable, buena prueba de la exigencia de garantizar un bien común frente a los beneficios particulares.

En paralelo, consciente de la necesidad de madera por los nuevos colonos, desde los primeros tiempos la monarquía reguló también el negocio maderero a través de disposiciones fundadas en costumbres de ascendencia probablemente islámica. Las primeras referencias jurídicas se remontan al privilegio que Jaime I otorgaba en Alcira el 30 de enero de 1267, por el que concedía plena libertad para transportar madera de cualquier clase y dimensiones a la ciudad de Valencia o a cualquier otra localidad del reino, franca y libremente, esto es exenta del pago de leuda o peaje, por vía terrestre como fluvial a través del Júcar y el Turia ${ }^{2}$. En relación a este privilegio, se dictaron diversos decretos reales contra aquellos que impidiesen o dificultasen el paso a la madera que circulaba por los ríos Turia, Júcar y Mijares.

En relación a estas prerrogativas destaca el derecho del cinquanté, una singular provisión destinada a asegurar el abastecimiento de las obras reales. Desde 1260 hay constancia de esta reserva otorgada fundamentalmente para el mantenimiento del castillo de Játiva, "que desde antiguo se exige y recibe como es costumbre, y ahora también exigimos de dicha madera" ${ }^{3}$. Con estos términos venía indicado cuando unos vecinos de Utiel obtuvieron del rey Jaime I franquicia de leuda y peaje para conducir madera por el Cabriel y el Júcar, con la condición de entregar un tronco de cada cincuenta, por lo que tomó el nombre de cincuenteno. Esta provisión constituye la primera referencia explícita relativa a este impuesto real que gravaba la entrega de una cincuentava parte de los troncos que descendían por el Júcar. En este sentido, para facilitar el tráfico fluvial Jaime I autorizaba a la villa de Alcira el 22 de diciembre de 1270 la apertura de un portillo de 25 palmos de ancho en una de las azudes del río (BRANCHAT, 1990). Estas disposiciones proporcionan las primeras noticias documentales sobre la procedencia de la madera y las principales vías de transporte a finales del siglo XIII. El recuento de la parte correspondiente al rey se realizaba "en el vado de Barragua de dicho río Júcar, a ración de nuestro castillo de Jàtiva". El paso de Barragá donde se hacía efectivo el reparto se hallaba en el valle de Cárcer, en la margen derecha del Júcar cerca de la desembocadura del río de Albaida. En efecto, la Crónica de Jaime I situaba el paraje en las proximidades de Alberique en el desaparecido lugar de Alcocer. Por ello, el área fue bautizada como Barca de Alcocer o Barca del rey y aún hoy permanece el recuerdo en un Camino de la Barca y una Casa de la Barca (VENTURA, 1986).

\footnotetext{
${ }^{2}$ Privilegio LXXIV de Jaime I. Concedido en Alcira el 30 de enero de 1267 (ALANYA et al. (eds.), 1999: 101).

${ }^{3}$ Archivo de la Corona de Aragón. Barcelona (en adelante ACA), 16, f. 196 (SANCHIS; PIQUERAS, 2001: 197).
} 
FIGURA 1

Vado de Barragá en el valle de Càrcer, en la desembocadura del río Albaida.

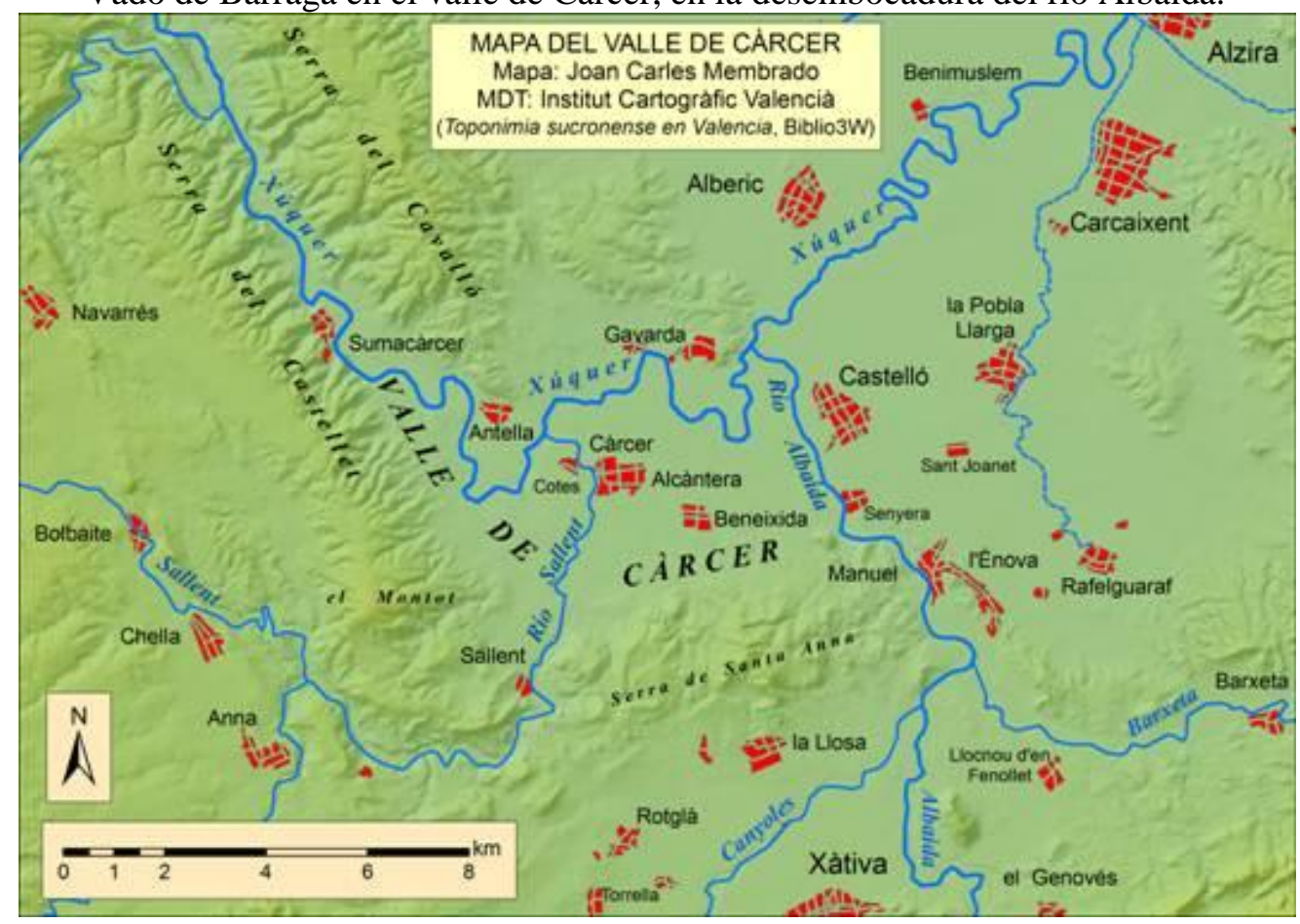

Fuente: Institut Cartogràfic Valencià

El cobro del cinquenteno, cinquantè o cinquentí, como se denomina en la documentación, queda justificado a través de pagos como el efectuado en 1280 por Simón de Arnedo por la madera que hacía conducir hasta Alcira (MARTÍNEZ FERRANDO, 1934). Con el tiempo, este derecho se haría extensible a toda la madera castellana que descendía por el Júcar (FERRER, 1990). Asimismo, su validez es manifiesta en las sucesivas intervenciones reales para exigir su cumplimiento, ya que la circulación de la madera por tres reinos complicaba su transporte y las tensiones ocasionadas por el choque de intereses entre los madereros y los propietarios de los terrenos a causa de la conducción fueron numerosas. Así, entre estas medidas se comprenden, por ejemplo, disposiciones como la dirigida por Pedro III en 1280 a los vecinos de Chelva para que no obstaculizasen a los habitantes de Arcos y Camarena la navegación de troncos hacia Valencia. Dos años más tarde, recordaba este mismo monarca los privilegios concedidos a los bailes y cobradores de peajes de los lugares del Júcar para que no impidiesen el paso de los troncos que el Infante Sancho de Castilla había donado a los frailes franciscanos de Alicante y Murcia para la construcción de sus conventos (MARTínEZ FERRANDO, 1934).

El espíritu de gran parte de estos decretos respondía a las pretensiones de los señores de los lugares por los que transitaba la madera, quienes impedían su paso para exigir el cobro del impuesto sobre las mercancías que atravesaban sus territorios, además de una compensación por los daños ocasionados por los maderos en las infraestructuras instaladas en las orillas. En este sentido, abundan ejemplos como el conflicto que surgió en 1315 entre el baile de Játiva Jaume Andreu y Gonzalo Zapata, perteneciente a la casa Borja, a causa de los impuestos sobre una cabaña de madera. Para eludir las cargas Gonzalo Zapata se había acogido a los fueros de Aragón, lo que constituía un intento evidente de estafa. No obstante, Jaime II se reservó las atribuciones sobre el caso, hasta que un año más tarde llegó a oídos del rey que los gancheros vendían de nuevo cierta cantidad de troncos antes de que llegasen al vado de Barragá para escapar así al pago ${ }^{4}$. Por ello, dispuso que toda la madera que descendía por el Júcar fuese

\footnotetext{
${ }^{4}$ La palabra ganchero identificaba a los encargados de conducir los troncos, para ello utilizaban una barra larga acabada en garfios para enganchar los maderos sueltos y encarrilarlos en el sentido de la corriente.
} 
sacada del agua al llegar al vado y que se cobrase el impuesto antes de que fuese vendida. Para evitar este tipo de fraudes, ordenó incluso que aquellos que escamoteasen el impuesto tendrían que pagar una multa de 100 sueldos reales valencianos. Si aún aguas abajo el baile de Alcira encontraba madera que no hubiese tributado al baile de Játiva, debía incautar a sus conductores posesiones o pertenencias equivalentes al valor de la multa ${ }^{5}$.

Naturalmente, esta medida suscitó protestas entre los propietarios de los terrenos a causa de las molestias ocasionadas por la madera que se extraía del río y se depositaba en los terrenos circundantes. Por ello, señores como Francesc de Pròixida obtuvieron una resolución judicial que prohibía el uso de sus tierras, aunque dada la necesidad y pese a arriesgarse a ser multados los gancheros continuaron dejando los maderos en la orilla. Finalmente, en pro del interés público y del físco, en marzo de 1318 Jaime II zanjó la cuestión autorizando el uso de las tierras siempre que los usuarios se comprometiesen a cubrir los costes de los desperfectos ocasionados $^{6}$. Aun así, pese a que la navegación fluvial se hallaba estrictamente regulada, no cesaron de producirse conflictos ocasionados tanto por la distinta legislación sobre la madera vigente en cada reino, como por los derechos de peaje que reclamaban los señores de las tierras que atravesaba. Por ello, en 1331 a propósito de una partida de pinos procedente de Castilla, Jaime II dictó privilegio por el que eximía del pago del peaje o pasaje en Cofrentes a la madera que se conducía desde los montes castellanos a través de los ríos Cabriel y Júcar. Con ello, el monarca recordaba a esta villa que debía respetar el derecho de franqueza, pues en ningún le estaba permitido cobrar el "diezmo y peaje por la madera por allí transeúnte" 7 .

Por otra parte, no sólo a la construcción se destinaba el cobro del cinquantè, puesto que constituía en realidad un derecho al que la monarquía recurrió a menudo para premiar los servicios de consejeros o camareros reales. Así lo muestra la orden de Pedro el Ceremonioso del 1 de agosto de 1336, en la que recordaba al baile de Játiva que por mandato de la reina Eleonor, viuda de Alfonso el Benigno, debía donar sesenta troncos al consejero Jimeno de Tovia, orden que el baile local había ignorado hasta el momento ${ }^{8}$. Igualmente, el 6 de septiembre de 1351 otorgaba el rey 300 troncos al alcaide de Játiva Pedro Vilanova en compensación por su fidelidad durante la guerra de la Unión que le había ocasionado la pérdida de su casa en Alcúdia9.

\section{MODIFICACIONES EN LA ADMINISTRACIÓN DEL CINQUANTÉ}

Al analizar el derecho del cinquanté es importante considerar ciertos aspectos relacionados con su gestión. En primer lugar, no siempre se cobró en Barragá, sino que en 1397 el rey Martín el Humano decidió trasladar el pago a la desembocadura del río en Cullera para abaratar de este modo los costes del impuesto sobre los troncos con destino a Barcelona. El cambio se preveía momentáneo, tan sólo mientras el rey necesitase madera para las reformas que pretendía iniciar en el palacio del Tinell, así como para proveer de madera la construcción de galeras en las atarazanas barcelonesas. Por lo tanto, estaba limitado a los troncos de mayor volumen, de modo que el impuesto sobre el resto de la madera continuó efectuándose en el lugar acostumbrado.

Además, algunos meses antes la reina María había mostrado interés por conocer los beneficios obtenidos del cinquantè en los últimos ocho o diez años. A pesar de que el administrador del impuesto era el baile de Játiva, la reina se dirigió al alcaide del castillo para averiguar el rendimiento práctico del tributo. Por desgracia, no conservamos la respuesta a la carta expedida por el rey en abril de este mismo año, por lo que no es posible determinar el volumen del negocio generado. No obstante, poseemos una noticia aislada que nos puede ilustrar sobre este aspecto, ya que en 1397 el baile obtuvo 42 maderos de pino carrasco por los

\footnotetext{
${ }^{5}$ ACA, Cancillería, reg. 243, ff. 54v-55r ( VENTURA, 1986: 48).

${ }^{6}$ ACA. Cancillería, reg. 244, f. 240 v (FERRER, 1990: 523).

${ }^{7}$ Privilegio CXXXII de Jaime II (ALANYA et al., 1999: 201).

${ }^{8}$ ACA. Cancillería, reg. 864, f. 82v (FERRER, 1990: 523).

${ }^{9}$ ACA. Cancillería, reg. 894, f. 5r (FERRER, 1990: 523).
} 
que consiguió 70 sueldos, lo que implica que ese año el volumen de maderos que circularon por el Júcar fue de $2.100 .^{10}$ El último dato de que se tiene noticia se remonta a 1402 cuando se requisaron 28 troncos, lo cual induce un total de 1.400 piezas. A partir de esta fecha, el cobro se interrumpió, sin que puedan establecerse motivos claros para ello, aunque García Marsilla (1997) sugiere que tal vez la causa resida en los conflictos políticos. En cualquier caso, a partir de este momento el abastecimiento de madera para las obras del castillo se efectuó también por vía terrestre desde la Canal de Navarrés, como sucedió en 1410 con la compra de piezas ya talladas a carpinteros mudéjares de Chella y Bolbaite ${ }^{11}$. Con todo, la continuidad y validez de este privilegio queda atestiguada aún en adelante, cuando en 1415 Fernando I recordaba los privilegios concedidos a Alcira respecto al uso de las aguas, e insistía en la obligación de permitir el paso de barcos y maderos que navegasen en el río ${ }^{12}$.

Sobre el emplazamiento del recuento de los maderos, a mediados del siglo XV se menciona una nueva modificación y se designa Antella como lugar para el cobro del impuesto. Así se induce de la causa abierta por el baile de Játiva en 1448 contra unos contratistas y comerciantes de madera que se negaban a pagar a los gancheros contratados para conducir hasta Alcira la partida correspondiente al cinquanté extraída en Antella. En efecto, los comerciantes no sólo debían satisfacer el pago sino que debían encargarse también de la conducción fluvial de los maderos hasta Alcira, donde serían cargados en carros para llevarlos definitivamente al castillo setabense, puesto que el trayecto entre Antella y Alcira no era apto para su transporte terrestre.

Finalmente, dado que para transportarlos a Játiva era más conveniente descargarlos en Alcira, una vez más se traslada la recaudación, esta vez al paso de la madera por el arrabal de San Agustín de Alcira (BRANCHAT, 1785). Desconocemos la fecha exacta en que se dispuso el cambio, pero así lo indican las comisiones del baile general a los procuradores del castillo de Játiva para que se desplazasen "a Alcira a cobrar el derecho del cinquantè" (ARCINIEGA, 2011). En realidad, el lugar resultaba más apropiado puesto que en su tránsito por la villa el cauce creaba una isleta que permitía desviar los maderos del sentido descendente del caudal hacia a un punto interior, donde era más fácil proceder al recuento y tomar la cantidad exigida para proveer la región antes de que el grueso de la partida prosiguiera su viaje hacia Cullera. Para asegurar el paso de los troncos en septiembre de 1405 se prohibió incluso la disposición de almadías de maderas en el río en los alrededores del arrabal de San Agustín, con una pena de sesenta sueldos a quien infringiese la orden ${ }^{13}$.

\footnotetext{
${ }^{10}$ Archivo del Reino de Valencia. Valencia (en adelante citado ARV). Maestro racional, 3.014, f. 10r (GARCÍA MARSILLA, 1997: 488).

${ }^{11}$ ARV. Maestro racional, 3.015, f. 70v (GARCÍA MARSILLA, 1997: 488).

${ }^{12}$ ARV. Real Audiencia. Procesos, $3^{\mathrm{a}}, 605$, ff. 17v-20v.

${ }_{13}$ Archivo Municipal de Alcira. Alcira (en adelante AMA), Libre de diverses statuts e ordenacions fets per lo consell de la vila de Algezira, ff. 109v-110r. La disposición establecía Que nadie ose tener almadías de madera en el río de cara a la villa (LAIRÓN, 2001: 145).
} 
FigURA 2

Plano de la villa de Alcira rodeado por el Júcar, con los arrabales de san Agustín y santa María. 1721.

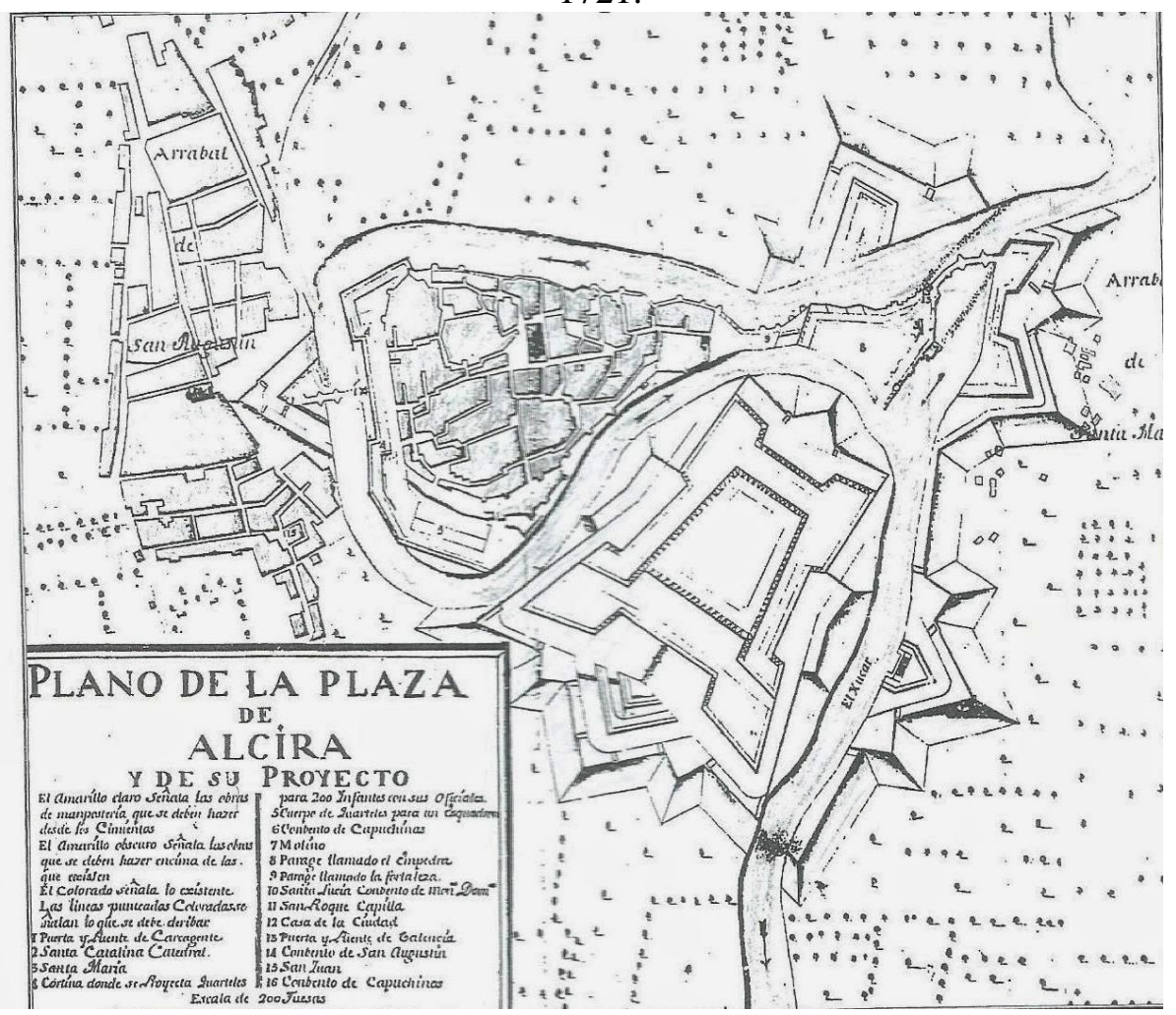

En cuanto a su tutela, por el cumplimiento del cinquantè velaba el baile general, como resulta evidente todavía el 15 de noviembre de 1468 en la orden a Luís Casanova para que escogiese "de la mejor que encontrarais, toda aquella madera que menester será a las obras del dicho castillo, y la que restará vendáis en pública subasta a quien mayor precio dará" ${ }^{14}$. El ciudadano de Játiva Luís Casanova era responsable de reunir, distribuir y subastar las piezas de la gabela, así como de rendir posteriormente cuentas al baile. El 24 de diciembre de 1477 el encargo a Galcerán Castellar aclara perfectamente las razones por las que se cobraba un "derecho con privilegio de la majestad del señor rey [el cual] ha sido dado y consignado para las obras del castillo de la ciudad de Játiva"" . Así de explícito lo justificaba la solicitud a Galcerán Castellar para que se desplazara a Alcira y tomara "por manos [suyas] tantos de los dichos maderos según lo acostumbrado, como basten a pagar dicho derecho del cinquantè", madera de la que el cobrador debía justificar el uso que haría de ella.

Con todo, la necesidad de abastecer la región llevaría igualmente a la monarquía a conceder exenciones, como ocurrió en junio de 1486 cuando los carpinteros vecinos de Rubielos Domingo Martí, Antoni Luescano y Domingo Pastor, cabanyers ${ }^{16}$, denunciaron ante el baile general a los cobradores del derecho peaje por no haber respetado la carta de franqueza otorgada por Fernando II $^{17}$.

\footnotetext{
${ }^{14}$ ARV. Bailía General. Letras y Privilegios, 1.154, ff. 273v-274r.

${ }^{15}$ ARV. Bailía General. Letras y Privilegios, 1.155, f. 788.

${ }^{16}$ Con el termino de cabanyer se identificaba al propietario de la cabanya o almadía de troncos.

${ }^{17}$ ARV. Bailía General. Letras y Privilegios, 1.149, f. 164r.
} 


\section{LA RIBERA DEL JÚCAR, REGIÓN ABASTECEDORA DE MADERA EN LA BAJA EDAD MEDIA}

Aunque los montes turolenses y la serranía de Cuenca fueron las principales regiones proveedoras de madera para la carpintería valenciana durante los siglos XIV y XV, en esta época la ribera del Júcar fue asimismo un territorio de abastecimiento de troncos destinados a la construcción (IZQUIERDO, 2014). Su importancia destacaba ya en el mandato del rey Alfonso IV al justicia de Alcira en 1290 para que investigase una tala irregular de árboles en el lugar de Cotes y procediese contra los autores y sus cómplices (GALLOFRE, 1968: documento 1659). El lento y pausado crecimiento de un árbol obligaba a las autoridades a velar para que las talas fuesen selectivas y controladas y no dañasen los terrenos. Por ello, cada abatimiento requería una licencia expresa del rey y siempre se limitaba a un cierto número de ejemplares que los agentes locales se encargaban de verificar, anotando en el dorso de la concesión la cantidad de árboles derribados a medida que eran talados (FERRER, 1990). Consecuentes con la escasez de madera para la construcción, la intención de la mayor parte de los decretos reales fue ante todo facilitar la llegada de madera de calidad a las villas y ciudades del litoral. En este sentido, ese mismo año Alfonso IV otorgaba franquicia de impuestos a la madera destinada al convento de San Agustín de Alcira (GALLOFRE, 1968: documento 713).

El transporte de tanta madera por el río pronto estimuló en la comarca la implantación de actividades relacionadas con el trabajo en carpintería. Así, ya en junio de 1320 Jaime II concedía a Pere Calderó, preceptor del infante Ramón Berenguer, los derechos para establecer un molino aserrador cerca de Játiva. Incluso lo autorizó a utilizar el agua del río necesaria para su funcionamiento, que podía desviar hacia el molino a través de cualquier propiedad, a condición de indemnizar a su dueño según la estimación del baile local ${ }^{18}$.

En efecto, a principios del s. XV los alrededores de Alcira estaban poblados de álamos, hasta el punto de ser la región abastecedora de la madera necesaria para las diez galeras que Fernando I mandó construir en las atarazanas de Valencia. El carpintero de ribera Jaume Mealler se trasladó expresamente al lugar para seleccionar los árboles apropiados (GUIRALHADZIIOSSIF, 1989). La humedad del área, irrigada por el río que circundaba la ciudad propiciaba la abundancia de especies salicáceas como el álamo blanco, ampliamente utilizado en la industria naval. Este tipo de encargos atestiguan la riqueza arbórea de las proximidades de Alcira. De hecho, en 1407 para la construcción de la galera de Santo Tomás en las atarazanas del Grao se adquirieron veintiún álamos a razón de once sueldos cada uno, conforme a la tasación efectuada por Jaume Mealler ${ }^{19}$. La importancia de Alcira como centro maderero la destacaba igualmente el síndico de la villa en 1416, al resaltar que en la "villa de Algezira, donde hay gran carpintería, así de pino doncel como de carrasca, en la cual villa se hace gran tráfico e mercadería... y de la dicha villa descendiendo por el río es llevada con almadías, como con otros, a la villa de Cullera y de aquí a Valencia, a Barcelona, a Gandia y a otras partes" (FURIÓ et al., 1993-1994).

Su papel como área de aprovisionamiento destacó especialmente en el suministro de madera de carrasca, probada a través de una interesante comisión que emprendieron el presbítero Joan Sanou, delegado de las obras de la Catedral, y el maestro carpintero Joan Amorós en julio de 1435. El objetivo era conseguir madera de carrasca de gran calidad para reemplazar el bastidor del campanario mayor, "que estaba en peligro de caer por falta de armazón, porque el que tenía estaba muy deteriorado y podrido" ${ }^{20}$. Las pautas de la selección de los árboles se ajustaron a las donaciones piadosas con las que propietarios de terrenos obsequiaban a menudo al cabildo catedralicio. En este caso, Miguel de Centelles ofrecía dos carrascas "en el término de Llombai" y Pedro Bou "dio otras dos en el carrascal de Quotes". Dado que se trataba de donaciones devotas, el patrón de búsqueda y selección de la madera se basó únicamente en la calidad de los

\footnotetext{
${ }^{18}$ ACA, Cancillería, reg. 218, f. 66r (FERRER, 1990: 524).

${ }^{19}$ ARV. Mestre Racional, 10.355, f. 28 r (IZQUIERDO, 2011: 116).

${ }^{20}$ ACV. Libros de fábrica de la Catedral, 1.479, ff. 42- 43 (IZQUIERDO, 2011: 116).
} 
maderos, evaluada por un experimentado carpintero que se trasladó al lugar para indicar los árboles adecuados: aquellos con mayores dimensiones y con el tronco bien enderezado, que proporcionarían vigas largas y rectas. Los criterios de elección escapaban a cualquier consideración sobre los decretos relativos al patrimonio forestal, pues no se trataba de una venta en la que había que calcular el precio de la cantidad adquirida. Este modelo de selección de la madera, que podríamos calificar de institucional, era preeminente en las obras reales y en los proyectos públicos, tanto en la renovación de castillos y lugares reales como en la construcción o reparación de infraestructuras (IZQUIERDO, 2014).

En el territorio valenciano la presencia de poblaciones de carrasca se veía favorecida por las condiciones del piso meso-mediterráneo subhúmedo, que se adecuaba perfectamente a las exigencias de la Quercus illex o de la variedad Quercus rotundifolia. El carrasco es un árbol perennifolio de una altura media entre los 16 y los 25 metros, de floración tardía de marzo a mayo, que madura las bellotas entre octubre y noviembre (SANTOLALLA, 2003). Es una especie resistente al calor, que crece en zonas cálidas y poco húmedas. Se sitúa siempre buscando la solana y se extiende principalmente por áreas levantinas meridionales, desde el nivel del mar hasta los 1.100 metros como máximo, ya que soporta tanto las bajas temperaturas como la sequía. Ofrece una madera resistente, sólida y flexible, con una óptima respuesta a la compresión. El Filarete (1400-1469) recomendaba su uso en la construcción por su capacidad de soportar grandes cargas. También Alberti (c. 1450) destacaba esta cualidad al aconsejar su uso para las cimentaciones, ya que gracias a sus minúsculos poros no absorbe la humedad. La idoneidad medio ambiental de la región abonó la presencia de bosques de carrascas, que constituyeron en realidad la auténtica vegetación en las zonas mediterráneas semiáridas del Camp de Turia y la Canal de Navarrés. Debido a la sobreexplotación agrícola del área, en la actualidad quedan muy pocos ejemplos de estos antiguos bosques por lo que los carracos son sólo residuales en algunos valles y barrancos que no han sido cultivados, donde se pueden hallar todavía buenos testimonios repartidos por toda la comarca (COSTA et al., 1982).

La búsqueda de las dos carrascas para construir el armazón de la campana mayor del campanario de la catedral comenzó el 25 de noviembre de $1435^{21}$. El cometido de la delegación era encontrar los árboles, verificar la calidad de su madera y dirigir la tala y el transporte de los troncos hasta Valencia. En este sentido, el documento es un memorial precioso que describe con detalle los hábitos desarrollados para la búsqueda de estas "buenas carrascas gruesas" situadas en el término de Llombai y en el carrascal de Cotes. En efecto, el administrador registró el tiempo empleado, los medios de transporte, los gastos en comidas y alojamiento en posadas, así como las dificultades que encontraron para localizar maderos de la especie requerida con la calidad apropiada.

La urgencia de la reparación explica los gastos que comportó el desplazamiento de Joan Sanou junto al maestro carpintero Joan Amorós "con un moro suyo". A Llombai llegaron al día siguiente, pero decidieron retrasar la tala porque "la luna no buena para talar, cuando fue buena la luna para talar las dichas carrascas fuimos a Llombai, jueves a 9 de diciembre del dicho año que fue la luna creciente". Dentro de la complejidad del proceso, se tuvo en cuenta la importancia de la buena luna en la tala. Pese a los inconvenientes que ocasionaba, se observó rigurosamente la incidencia de las fases lunares sobre el volumen de la linfa de la planta en el momento de su abatimiento, que por tradición se creía que dependía fundamentalmente del emplazamiento del árbol y del tiempo del corte. Más allá del debate sobre la veracidad de las propuestas al respecto, lo cierto es que la Edad Media heredó la tradición legada por los tratadistas antiguos al observar la influencia de la luna sobre la calidad final de la madera y obtener así mayor resistencia a la putrefacción y al ataque de insectos. Las observaciones recogidas en los archivos medievales valencianos recomendaban preferentemente los días de luna menguante para la tala de los árboles de hoja caduca, mientras que la luna creciente resultaba más favorable para los perennifolios (GARCÍA MARSILLA; IZQUIERDO, 2013).

\footnotetext{
${ }^{21}$ Archivo de la Catedral de Valencia. Valencia (en adelante ACV). Libros de fábrica de la Catedral, 1479, años 1434-1435, f. 42-43 (IZQUIERDO, 2011: 508-509).
} 
De este modo, pese a las incomodidades del viaje, la conveniencia de esperar a la luna creciente justificaba el retraso de las obras y los gastos añadidos. Durante el proceso del derribo de las carrascas, se consignaron los trabajos realizados par Joan Amorós, así como las tareas de los carpinteros contratados para ayudar "a derribar las carrascas". Esto nos permite conocer los procedimientos empleados y las complicaciones planteadas según las particularidades de cada árbol, "porque una carrasca era sobre elevada" y su altura complicaba las labores o a causa de las dificultades añadidas por el mal estado de los caminos para el transporte de las herramientas y de los maderos "por los malos pasos y caminos que eran por lluvias que les sobrevinieron".

En la arquitectura gótica valenciana su empleo está documentado asimismo en los portales mayores de les atarazanas del Grao de Valencia, gracias a la compra efectuada el 28 de enero de 1407 por Pere Olomar a Pere Agost, vecino de Silla, de "trece carrascas en su posesión" a razón de dos sueldos cada una. También se utilizaba para la confección de ejes de carros y grúas, como muestra la adquisición del 23 de julio de 1452 de una arroba de carrasca al carpintero Pere Bolufer, responsable de la construcción y el mantenimiento de la grúa de la Capilla Real del convento de Predicadores ${ }^{22}$.

\section{CONCLUSIONES}

El territorio valenciano es una zona de contacto de dos grandes sierras peninsulares: el Sistema Ibérico al norte y el Sistema Bético al sur. Así, en el medievo las condiciones geológicas y geográficas del reino de Valencia, no menos que las circunstancias políticas, obligaron a dirigirse hacia regiones interiores para proveerse de madera. Dado que los árboles se localizaban en áreas montañosas de difícil acceso, la navegación fluvial se impuso como el medio más rápido y económico, favorecido por la circunstancia de que los ríos Júcar, Turia, Mijares y Cabriel nacen en estas sierras y constituyeron las vías naturales para el transporte de los troncos. En efecto, está documentada desde el siglo XII en las descripciones del geógrafo Mohamed Al-Idrisi acerca del descenso de los troncos por el Júcar y su posterior embarco en Cullera con destino a Denia y Valencia. Tras la conquista cristiana, los decretos reales emitidos para garantizar el abastimiento y amparar el transporte resultan referencias substanciales para conocer los criterios empleados. En este sentido, fue primordial el impulso dado por Jaime I en el privilegio de 1270 al eximir de impuestos de leuda y peaje la madera que descendía por los ríos. Las intervenciones reales motivadas por los conflictos entre los madereros y los señores de las tierras que atravesaba dan testimonio de la dificultad de mantener este privilegio.

Precisamente por la circulación de maderos destinados a la construcción, el territorio circundante a la ribera del Júcar jugó un importantísimo papel en el abastecimiento de madera. Uno de los aspectos interesantes en esta participación fue el cinquantè o cincuenteno, que el Jaime I concedió para el mantenimiento del castillo de Játiva, desde 1260 tenemos constancia de esta reserva que gravaba un tronco de cada cincuenta de los que navegaban por el Cabriel y el Júcar. Finalmente, La Ribera destacó también durante los siglos XIV y XV como territorio de abastecimiento de troncos destinados a la construcción. En este sentido, el documento relativo a la búsqueda de madera de carrasca para la construcción del armazón de la campana mayor de la Catedral ofrece datos inéditos sobre los procedimientos empleados en la época para el examen de la calidad de la madera, así como de los trabajos y los costes que comportaban la tala y el transporte de los troncos.

\section{BIBLIOGRAFÍA}

ALANYA, L. et al., (eds.) (1999): Obra de oro de los privilegios reales de la ciudad y del reino de Valencia, con la historia del cristianísimo Rey Jaime, su primer conquistador. Ajuntament de València, València.

${ }^{22}$ ARV. Mestre Racional, signatura 9.251 (TOLOSA et al., 1997: 92). 
ALBERTI, L. B. (1450 ca): De re aedificatoria. En FRESNILLO NÚÑEZ, J. (Ed.) (1991). Akal, Torrejón de Ardoz.

Al-IDRISI, M. (1100-1165, ca.): Descripción de España. En GARCÍA MERCADAL, J. (Ed.) (1952-1962): Viajes de extranjeros por España y Portugal. Aguilar, Madrid.

ÁLVAREZ BORGE, I (2003): La plena Edad Media. Siglos XII-XIII. Madrid, Síntesis.

ARCINIEGA GARCÍA, L. (2011): La Cruz de los Tres Reinos. Espacio y tiempo en un territorio de frontera. "El abastecimiento fluvial de madera al Reino de Valencia". En MONTESINOS, J. et al. (eds.): Universidad de Castilla-La-Mancha, Cuenca.

AVERLINO, A. (1400-1469): Tratado de arquitectura. En Pedraza, P. (Ed. lit.) (1990). Instituto de Estudios Iconográficos EPHIALTE, Vitoria-Gasteiz.

BONNASSIE, P. et al. (2001): Las Españas medievales. Crítica, Barcelona.

BOSCH Y JULIÀ, M. (1866): Memoria sobre la inundación del Júcar en 1864 presentada al Ministerio de Fomento. Imprenta Nacional, Madrid.

BRANCHAT, V. (1785): Tratado de los derechos y regalías que corresponden al Real Patrimonio en el Reyno de Valencia. Generalitat Valenciana, València.

CEBRIÁN ABELLÁN, A. (2008): Papeles de geografia. "El patrimonio como potencial turístico de las comarcas del Júcar y Cabriel (Albacete), n 47-48, p. 35-53.

COSTA, M. et al. (1982). Lazarca. "Sobre los carrascales termomediterráneos valencianos", no 4, p. 37-52.

EIXIMENIS, F. (ca.1340-ca.1409): Regiment de la cosa pública. [Edición facsímil de Librerías París-Valencia, Valencia, 1991.]

FERRER I MALLOL, M. T. (1990): Anuario de estudios medievales. "Boscos i deveses a la Corona catalanoaragonesa (segles XIV-XV)", n² 20, p. 485-542.

FLORIDO TRUJILLO, G. (2004): Papeles de geografía. "Uso social y evolución del bosque Atlántico. Pasado y presente en el ámbito del bajo deba guipuzcoano", nº 39, p. 59-80.

FURIÓ, A. et al. (1993-1994): “Assuts i molins sobre el Xúquer en la Baixa Edat Mitjana”. En IV Congrés d'Arqueologia Medieval Espanyola. Asociación Española de Arqueología Medieval, Madrid, p. 575-583.

GALLOFRE GUINOVART, R. (1968): Documentos del reinado de Alfonso III de Aragón: relativos al antiguo reino de Valencia y contenidos en los registros de la Corona de Aragón. Institución Alfonso el Magnánimo, Valencia.

GARCÍA MARSILLA, J. V. (1997). Acta historica et archaeologica mediaevalia. "El mantenimiento de los recintos fortificados en la Valencia bajomedieval. Las reparaciones del castillo de Xàtiva (1410-1412)", no 18, p. 475-493.

GARCÍA MARSILLA, J. V. e IZQUIERDO ARANDA, T. (2013): Abastecer la obra gótica: el mercado de materiales de construcción y la ordenación del territorio en la valencia bajomedieval. Conselleria d'Infraestructures, Territori i Medi Ambient, València.

GUIRAL-HADZIIOSSIF, J. (1986): Valence, port méditerranéen au XVe siècle : (1410-1525). Publications de la Sorbonne, Paris.

IZQUIERDO ARANDA, T. (2011): El fuster, definició d'un ofici en la València medieval. (Tesis doctoral) Universitat de València, València.

IZQUIERDO ARANDA, T. (2014): La fusteria en la València medieval (1238-1520). Publicacions de la Universitat Jaume I, Castelló de la Plana.

LAIRÓN PLA, A. J. (Ed.) (2001): Libre de diverses statuts e ordenacions fets per lo consell de la vila de Algezira. Universitat de València, València.

MARTÍNEZ FERRANDO, J. E. (1934): Catálogo de la documentación relativa al antiguo reino de Valencia: contenida en los registros de la Cancillería Real. Cuerpo Facultativo de Archiveros, Bibliotecarios y Arqueólogos, Madrid.

SAAVEDRA, E. (1881): La geografía de España de Eldrisi. Imprenta de Fortanet, Madrid.

SANCHIS DEUSA, C. y PIQUERAS HABA, J. (2001): Cuadernos de Geografía. "La conducció fluvial de fusta a València (segles XIII-XX)", nº 69-70, p. 195-214.

SANTOLALLA, F. (2003): Guía de los árboles de la Península Ibérica y Baleares. Blume, D. L., Barcelona. 
TOLOSA, L. et al. (1997): La capella reial d'Alfons el Magnànim de l'antic monestir de predicadors de Valencia. "Documents per a la història d'una construcció". En ZARAGOZÁ CATAlÁN, A. (Ed.). Direcció General de Promoció Cultural, Museus i Belles Arts, València.

VENTURA, A. (1986): Les demarcacions històriques de la Xàtiva foral. Fira d'agost, Xàtiva.

VITRUVIO POLIÓN, M. (23-27 a.C.): Los diez libros de arquitectura. En Oliver Domingo, J. L. (Trad.) (1995). Alianza, Madrid. 